\title{
Morphometric Study of the Acromion Process and its Clinical Relevance
}

\author{
Gursharan Singh Dhindsa', Vishal Gupta ${ }^{2}$ \\ ${ }^{1}$ Associate Professor, Department of Anatomy, Guru Gobind Singh Medical College \& Hospital, Faridkot, Punjab, India, ${ }^{2}$ Associate Professor, Department of \\ Community Medicine, Guru Gobind Singh Medical College \& Hospital, Faridkot, Punjab, India.
}

\section{Abstract}

Background: The acromion process along with the coracoid process and the coracoacromial ligament form the coracoacromial arch which acts as a secondary socket for the shoulder joint. The subacromial space gives passage to the tendons of muscles forming the rotator cuff. Any abnormality, acquired or congenital, which leads to the reduction in the subacromial space can cause impingement syndrome. Morphology of the acromion thus plays an important role in impingement syndrome and the pathogenesis of rotator cuff diseases. Subjects and Methods: A total of 70 Indian unpaired dry human scapulae (Right-35, Left-35) of unknown sex were studied. Various parameters related to acromion process- a) Maximum length of acromion b) Maximum breadth of acromion c) Acromio-Glenoid distance and e) Acromio-Coracoid distance were measured with the help of a sliding digital vernier caliper and recorded in millimeters. Results: The mean values of each measurement were: maximum length of acromion: $43.10 \mathrm{~mm}$; maximum breadth acromion: $24.46 \mathrm{~mm}$; acromio- glenoid distance: $30.15 \mathrm{~mm}$ and acromiocoracoid distance: $37.05 \mathrm{~mm}$. Conclusion: Knowledge of the morphometeric values of acromian process is important to the orthopaedicians in the differential diagnosis and surgical treatment of shoulder joint ailments, to the forensic experts in specimen identification from skeleton remains and to the anthropologists in their racial and population studies.

Keywords: scapula, acromion process, morphometry, impingement syndrome.

Corresponding Author: Dr. Gursharan Singh Dhindsa, Associate Professor, Department of Anatomy, Guru Gobind Singh Medical College \& Hospital, Faridkot, Punjab, India.

Received: September 2019

Accepted: September 2019

\section{Introduction}

The scapula (shoulder blade) bears three processes- the spine, the acromion and the coracoid process. The acromion is a large, triangular/oblong prolongation of the lateral end of the spine, forming the summit of the shoulder. At the acromial angle, the lateral border of the acromion becomes continuous with the lower border of the crest of the spine. The medial border of the acromion is short and is marked anteriorly by a small, oval facet, for articulation with the lateral end of the clavicle. The acromion is subcutaneous over its dorsal surface, being covered only by the skin and superficial fascia. The inferior aspect of the acromion is smooth, and together with the coracoacromial ligament and the coracoid process forms a protective coracoacromial arch over the shoulder joint. The tendon of supraspinatus passes below the overhanging acromion and is separated from it and from deltoid by the subacromial bursa. The subacromial bursa functions as a secondary synovial articulation, facilitating movement between the coracoacromial arch and the subjacent supraspinatus muscle and shoulder joint. ${ }^{[1]}$

The coracoacromial arch is non-elastic and the underneath subacromial space, contains the tendons of rotator cuff muscles and biceps brachii muscle. ${ }^{[2]}$ Any abnormality, acquired or congenital, which leads to the reduction in the subacromial space can cause impingement syndrome.
Paraskevas et al, ${ }^{[2]}$ reported that the length of the acromion has an effect on the acromio-glenoid distance and a shortening of this distance can predispose to impingement syndrome. Edelson et al, ${ }^{[3]}$ noted that the slope and length of the acromion and the height of the coracoacromial arch are most closely associated with degenerative changes.

The most relevant factor determining the height of subacromial space is morphology of the acromion and its relationship with the coracoid process and glenoid cavity as stated by Torres et al. ${ }^{[4]}$ Anetzberger et al, ${ }^{[5]}$ in their study concluded that it is the length and width of the acromion which plays an important role in the pathogenesis of impingement syndrome, leading to rotator cuff disease. Neer6 was the first to introduce the concept of Subacromial Impingement Syndrome representing mechanical compression of the rotator cuff, subacromial bursa, and biceps tendon against the undersurface of the acromion and coracoacromial ligament. Acromion morphology is believed to play a key role in impingement syndrome and the pathogenesis of rotator cuff diseases. ${ }^{[7]}$

Therefore, the present study to record the various parameters related to the acromion process was carried out which would be of help to the orthopaedicians while carrying out surgical repairs around the shoulder joint especially in cases of subacromial impingement syndrome, 


\section{Dhindsa of Gupta; Marphametric Study of the Acramian Pracess}

rotator cuff diseases etc.

\section{Subjects and Methods}

A total of 70 Indian unpaired right and left dry human scapulae of unknown sex were studied from teaching collection of the Anatomy department, GGS Medical College, Faridkot. Out of the total of 70 scapulae, 35 were of right side and 35 were of left side. All the scapulae selected were complete and showed normal anatomical features. Various parameters related to acromion process were measured with the help of a sliding digital vernier caliper and recorded in millimeters.

\section{The following measurements of the acromion process} were recorded:

1. Maximum Length of Acromion (MLA): distance between tip and midpoint of posterior border of acromion process. [Figure 1a.]

2. Maximum Breadth of Acromion (MBA): distance between the lateral and medial borders at the midpoint of the acromion process. [Figure 1b.]

3. Acromio-Glenoid distance (A-G distance): distance between tip of acromion process and supraglenoid tubercle. [Figure 1c.]

4. Acromio-Coracoid distance (A-C distance): distance between the tip of acromion and tip of the coracoid processes. [Figure 1d.]

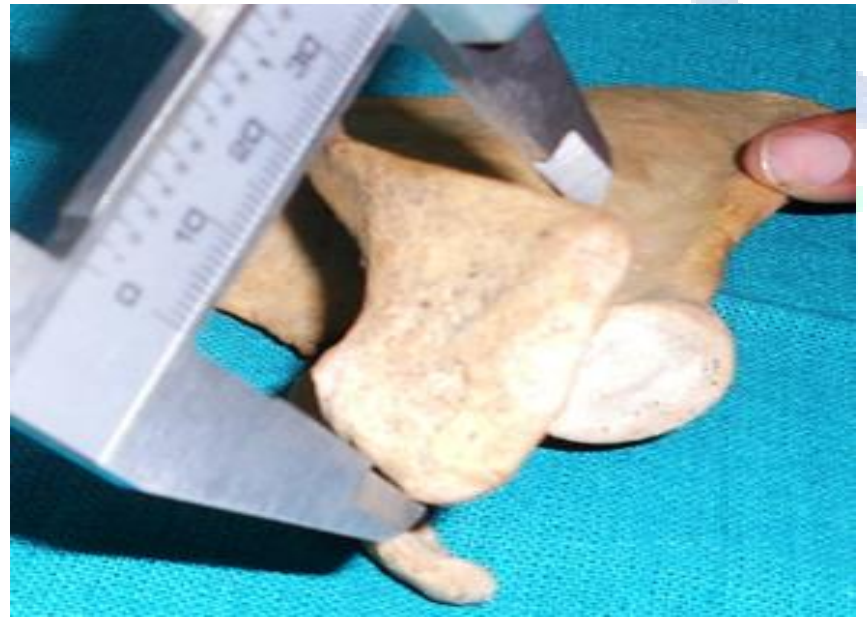

a) Maximum Length of Acromion (MLA)

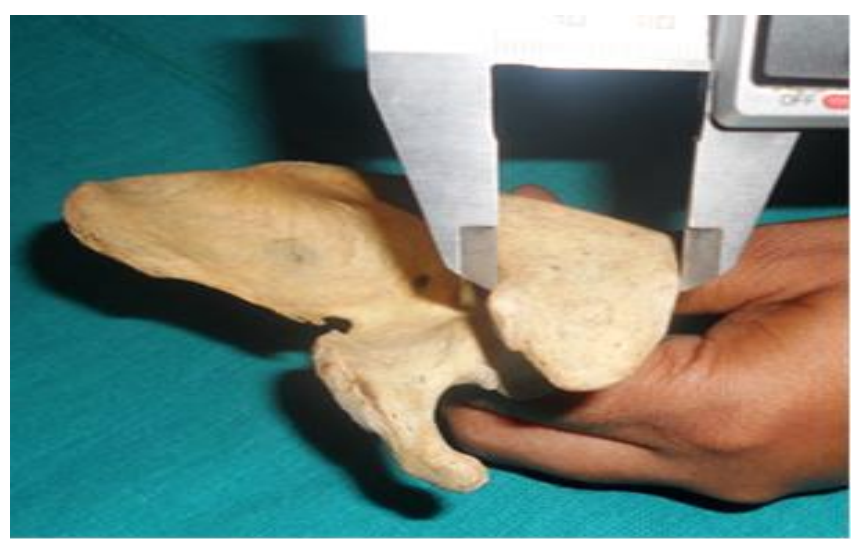

b) Maximum Breadth of Acromion (MBA)
The data was entered in the Microsoft Excel 2010 sheet and statistically analyzed, range, mean, standard deviation, standard error of mean, degree of freedom, $p$-value and $t$ value were calculated. Statistical analysis of the measured parameters was performed using paired $\mathrm{t}$ - test.

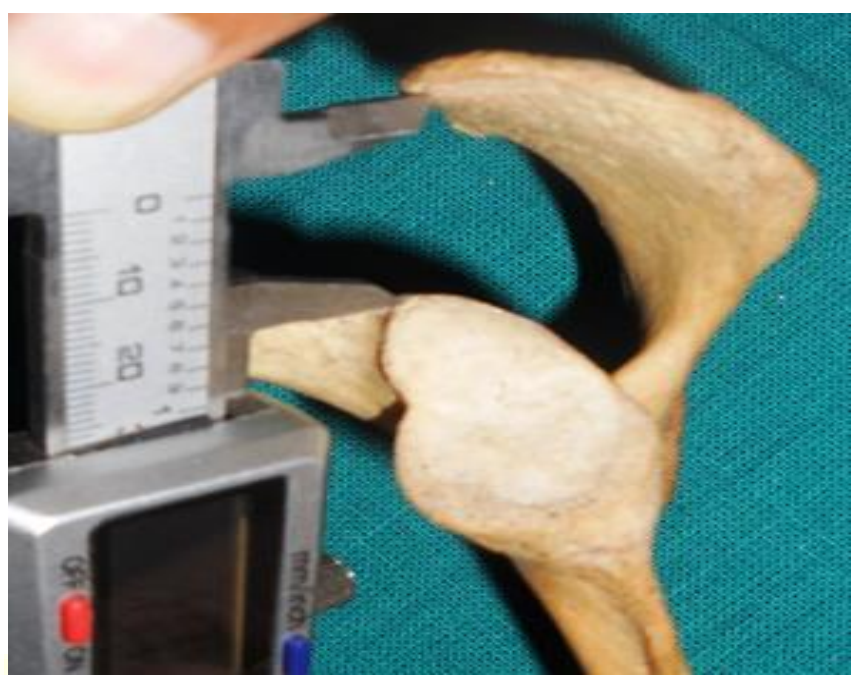

c) Acromio-Glenoid Distance(A-G distance)

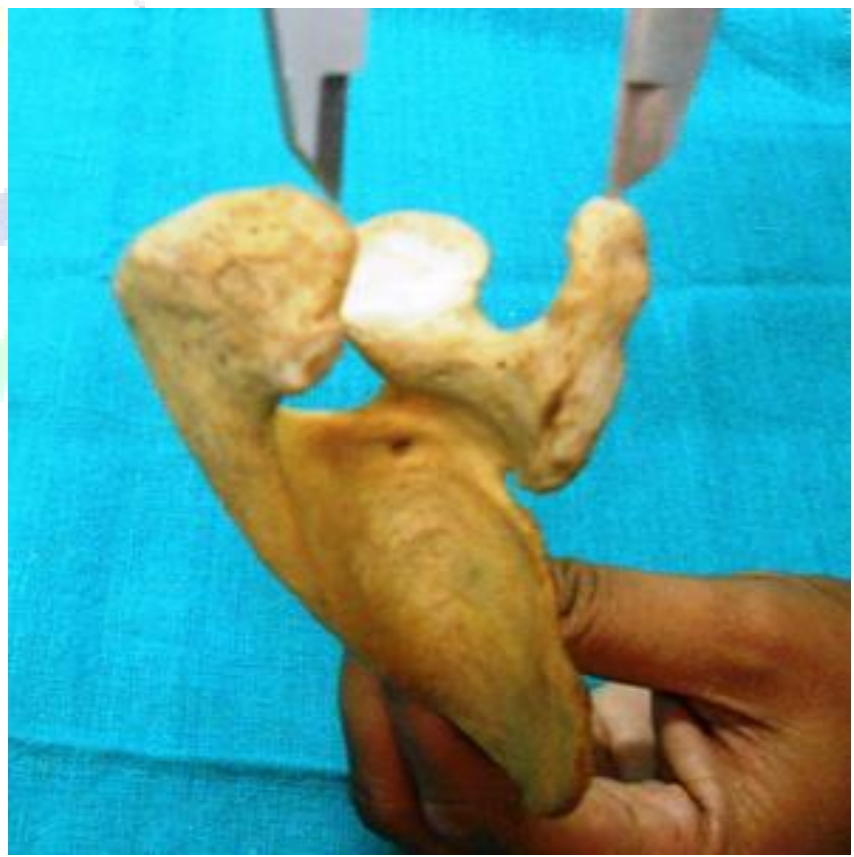

d) Acromio-Coracoid Distance(A-C distance)

Figure 1: Showing the measurement of different parameters of the Acromion Process

\section{Results}

In the present study, of the total 70 scapulae studied, 35 were of the right side and 35 of the left side. The mean value of acromion length was found to be $43.10 \mathrm{~mm}$ in total samples, $43.47 \mathrm{~mm}$ in right side and $42.74 \mathrm{~mm}$ in left side. The mean value of acromion breadth was found to be 24.46 $\mathrm{mm}$ in total samples, $24.86 \mathrm{~mm}$ in right side and in 24.06 left side. The mean acromio-glenoid distance observed in 
total samples was $30.15 \mathrm{~mm}, 30.03 \mathrm{~mm}$ in right side and $30.27 \mathrm{~mm}$ in left side. The mean acromio-coracoid process was found to be $37.05 \mathrm{~mm}$ in total sample, $36.14 \mathrm{~mm}$ in right side and 37.96 in left side. The mean length and breadth of acromion was more on the right side as compared to the left side whereas the mean acromio-glenoid distance and the mean acromio-coracoid distance was more on the left side, but the differences were statistically insignificant.

The values of various parameters of the acromion process recorded and calculated are shown in [Table $1 \& 2$ ].

Table 1: Statistical measurements of different parameters of Right and Left side Acromion

\begin{tabular}{|c|c|c|c|c|c|c|c|c|}
\hline \multirow[t]{2}{*}{ Parameters } & \multicolumn{4}{|l|}{ Right $(\mathbf{N}=35)$} & \multicolumn{4}{|l|}{ Left $(\mathrm{N}=35)$} \\
\hline & Range (mm) & $\begin{array}{l}\text { Mean } \\
(\mathrm{mm})\end{array}$ & $\begin{array}{l}\text { SD } \\
(\mathrm{mm})\end{array}$ & $\begin{array}{l}\text { SEM } \\
(\mathbf{m m})\end{array}$ & $\begin{array}{l}\text { Range } \\
(\mathrm{mm})\end{array}$ & $\begin{array}{l}\text { Mean } \\
(\mathrm{mm})\end{array}$ & $\begin{array}{l}\text { S D } \\
(\mathrm{mm})\end{array}$ & $\begin{array}{l}\text { SEM } \\
(\mathbf{m m})\end{array}$ \\
\hline MLA & $30.44-52.97$ & 43.47 & 5.33 & 0.90 & $28.39-54.59$ & 42.74 & 6.11 & 1.03 \\
\hline MBA & $20.11-32.71$ & 24.86 & 3.21 & 0.54 & $16.6-35.57$ & 24.06 & 3.17 & 0.54 \\
\hline A-G distance & $21.26-39.33$ & 30.03 & 3.66 & 0.62 & $21.22-40.92$ & 30.27 & 4.61 & 0.78 \\
\hline A-C distance & $26.28-48.42$ & 36.14 & 4.84 & 0.82 & $26.86-49.85$ & 37.96 & 5.76 & 0.87 \\
\hline
\end{tabular}

SD = Standard Deviation, SEM= Standard Error of Mean

Table 2: Result of paired t-test between acromion of Right \& Left Scapulae

\begin{tabular}{|l|l|l|l|}
\hline Parameters & $\begin{array}{l}\text { Degree of freedom } \\
\text { (Df) }\end{array}$ & t-Value & p-Value \\
\hline MLA & 68 & 0.530 & 0.598 \\
\hline MBA & 68 & 1.051 & 0.297 \\
\hline A-G distance & 68 & -0.235 & 0.815 \\
\hline A-C distance & 68 & -1.426 & 0.158 \\
\hline
\end{tabular}

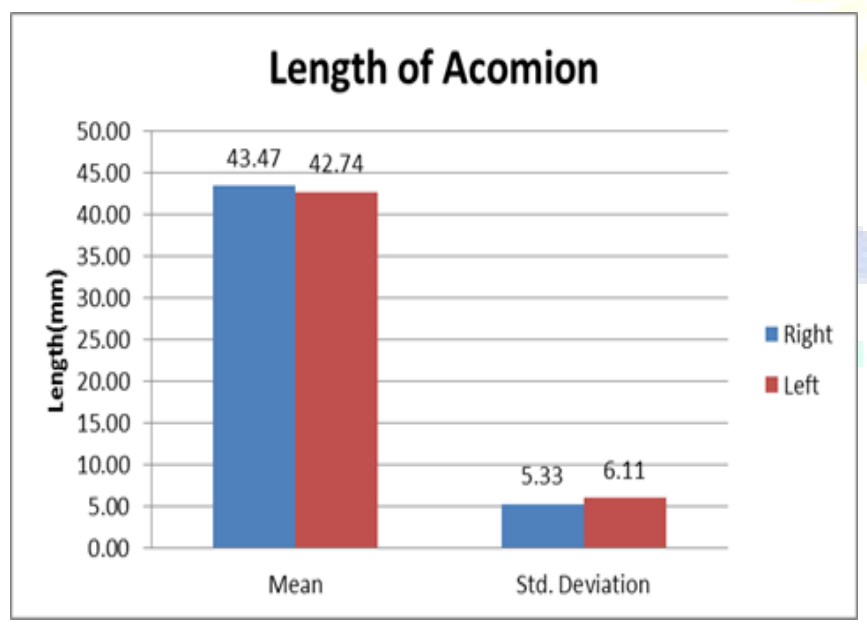

Graph1: Showing comparison of Mean \& Standard Deviation of Length of Acromion of Right \& Left Scapulae

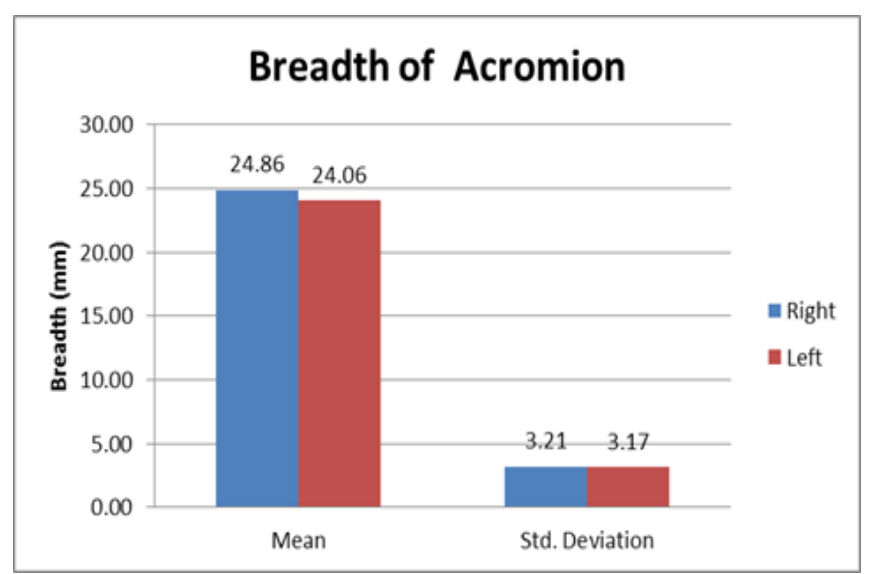

Graph 2: Showing comparison of Mean \& Standard Deviation of Breadth of Acromion of Right \& Left Scapulae

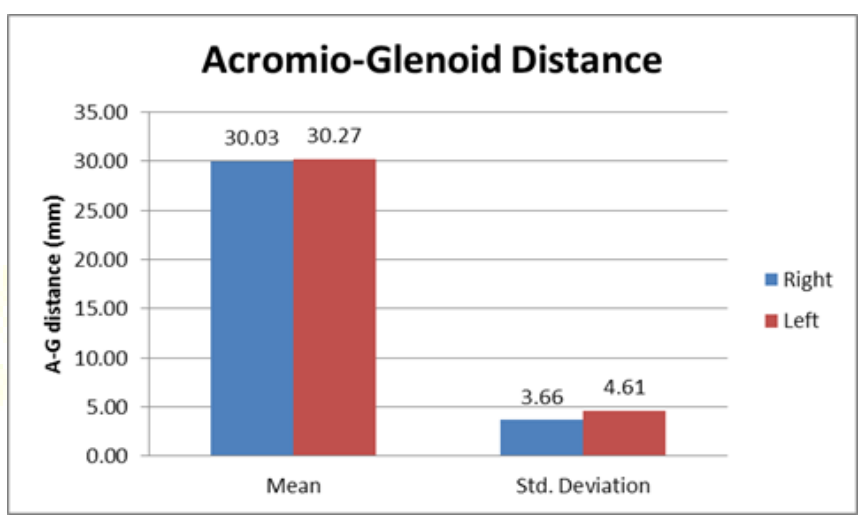

Graph 3: Showing comparison of Mean \& Standard Deviation of Acromio-Glenoid Distance of Right \& Left Scapulae

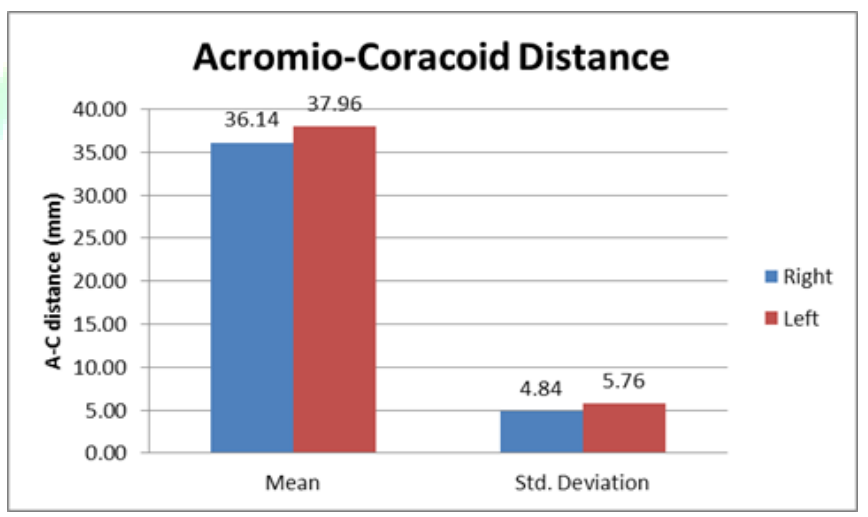

Graph 4: Showing comparison of Mean \& Standard Deviation of Acromio-Coracoid Distance of Right \& Left Scapulae

\section{Discussion}

The human scapula has undergone the greatest alterations among the bones of the shoulder girdle, during the process of evolution of the upper limb due to the increased functional demands of a prehensile limb. During development there has been a gradual increase in the spine and the acromion process of the scapula. ${ }^{[8]}$ The morphological parameters of the acromion provide a significant contribution to the anatomy of the coracoacromial arch and the subacromial space. Studies 
conducted by various authors around the different regions of the world have revealed the relation between morphology of the acromion process and subacromial impingement syndrome and rotator cuff pathology which causes shoulder pain. $^{[2-7]}$

Maximum Length of Acromion: In the present study the mean maximum length of acromion was found to be $43.10+5.70 \mathrm{~mm} \quad($ Right $=43.47+5.33 \quad \mathrm{~mm} \quad \&$ Left $=42.74+6.11 \mathrm{~mm})$ and the range was between $28.39 \mathrm{~mm}-54.59 \mathrm{~mm}$ (Right=30.44-52.97 $\mathrm{mm}$ \& Left= 28.39- $54.59 \mathrm{~mm}$ ). Wael Amin et al, ${ }^{[9]}$ reported the length of acromion to be $52.81 \mathrm{~mm}$ in Egyptians. Mansur DI et al, ${ }^{[10]}$ recorded length of acromion to be $46.46 \mathrm{~mm}$ on right side and $45.57 \mathrm{~mm}$ on left side in Nepalese population whereas a value of $40 \mathrm{~mm}$ was reported by Sitha $P$ et ${ }^{a},{ }^{[11]}$ in Thai population and $46.1 \mathrm{~mm}$ by Paraskevas et al, ${ }^{[2]}$ in Greeks. Lingamdenne PE et al, ${ }^{[12]}$ reported mean length of $43.22 \mathrm{~mm}$ in South Indian population, which is very close to our study. Maximum Breadth of Acromion: The mean maximum breadth of acromion in the present study was found to be $24.46+3.19 \mathrm{~mm}(\mathrm{Right}=24.86+3.21 \mathrm{~mm} \&$ Left $=24.06+$ $3.17 \mathrm{~mm}$ ) and the range was between $16.6 \mathrm{~mm}-35.57 \mathrm{~mm}$ $($ Right $=20.11-32.71 \mathrm{~mm} \&$ Left $=16.6-35.57 \mathrm{~mm})$. Wael Amin et $a l,{ }^{[9]}$ reported the breadth of acromion to be $32.05 \mathrm{~mm}$ in Egyptians. Mansur DI et $\mathrm{al},{ }^{[10]}$ recorded breadth of acromion to be $26.63 \mathrm{~mm}$ on right side and 27.23 $\mathrm{mm}$ on left side in Nepalese population whereas a value of $23.9 \mathrm{~mm}$ was reported by Sitha $\mathrm{P}$ et $\mathrm{al},{ }^{[11]}$ in Thai population and $22.3 \mathrm{~mm}$ by Paraskevas et al in Greeks. ${ }^{[2]}$ Lingamdenne PE et al, ${ }^{[12]}$ reported mean breadth of 24.64 $\mathrm{mm}$ in South Indian population, which is very close to our study.

Acromio-Glenoid distance: In the present study the mean acromio-glenoid distance was found to be $30.15+4.13 \mathrm{~mm}$ $($ Right $=30.03+3.66 \mathrm{~mm} \&$ Left $=30.27+4.61 \mathrm{~mm})$ and the range was between $21.22 \mathrm{~mm}-40.92 \mathrm{~mm}$ (Right=21.26$39.33 \mathrm{~mm} \& \mathrm{Left}=21.22-40.92 \mathrm{~mm}$ ). Wael Amin et al, ${ }^{[9]}$ recorded the acromio-glenoid distance to be $27.39 \mathrm{~mm}$ in Egyptian population. The acromio-glenoid distance measured by Mansur DI et al, ${ }^{[10]}$ was $31.83 \mathrm{~mm}$ and 31.97 $\mathrm{mm}$ on right and left side respectively in Nepalese population. It was reported to be $18.1 \mathrm{~mm}$ in Thai population 11, $17.7 \mathrm{~mm}$ in Greek population 2 and $24.46 \mathrm{~mm}$ in South Indian population 12. The present study readings are close to that of Mansur DI et al, ${ }^{[10]}$ recorded in Nepalese population.

Acromio-Coracoid distance: The mean acromio-coracoid distance in the present study was found to be37.05+5.36 $\mathrm{mm}($ Right $=36.14+4.84 \mathrm{~mm} \&$ Left $=37.96+5.76 \mathrm{~mm})$ and the range was between $26.28 \mathrm{~mm}-49.85 \mathrm{~mm}$ (Right $=26.28$ $48.42 \mathrm{~mm} \&$ Left=26.86-49.85 mm). The acromio-coracoid distance found by Wael Amin et al, ${ }^{[9]}$ was $31.34 \mathrm{~mm}$ in Egyptians. Mansur DI et al, ${ }^{[10]}$ recorded it as 39.03 on the right side and $39.39 \mathrm{~mm}$ on left side in Nepalese population. It was reported to be $14.8 \mathrm{~mm}$ in Thai population11, 28.1 $\mathrm{mm}$ in Greek population2 and $31.85 \mathrm{~mm}$ in South Indian population 12. Singh $\mathbf{J}$ et al, ${ }^{[13]}$ reported it to be $37.5 \mathrm{~mm}$ in
North Indian Population. The readings reported by us are close those reported by Singh J et al. ${ }^{[13]}$

In the present study, it can be noted that although the mean length and breadth of the acromion process on the right side was slightly more than the left side but that does not represent statistically significant differences. Similarly, the mean acromio-glenoid distance and the mean acromiocoracoid distance were slightly more on the left side, but the differences were again statistically insignificant. The differences in the readings of different authors can be attributed to regional and racial variations.

\section{Conclusion}

The overall goal of this study was to generate data that would be useful to the orthopaedicians in their differential diagnosis and surgical treatment of shoulder pains. The study would also help the forensic experts in specimen identification from skeleton remains. It would also be valuable for the anthropologists not only in their racial and population studies but also in their studies about the human evolution.

\section{References}

1. Johnson D. Pectoral Girdle, Shoulder region and Axilla. In: Standring S, Borley NR, Collins P, Crossman AR, Gatzoulis MA, Healy JC, et al, editors. Gray's Anatomy, The Anatomical Basis of Clinical Practice. 40th ed. Churchill Livingstone; 2013. p. 791-822.

2. Paraskevas G, Tzaveas A, Papaziogas B, Kitsoulis P, Natsis K, Spanidou S. Morphological parameters of the acromion. Folia Morphol (Warsz) 2008; 67: 255- 60.

3. Edelson JG, Taitz C. Anatomy of the coracoacromial arch. J Bone Joint Surg (Br) 1992; 74-B: 589-94.

4. Torres CA, Riberio CS, Maux SXDA, Oliveria GCD, Neves MG, Salgado ARF, et al. Morphometry of acromion process and its clinical importance. Int J Morphol. 2007; 25(1):51-54.

5. Anetzberger H, Putz R. The scapula: principles of construction and Stress. Acta Anat (Basel) 1996; 156: 70-80.

6. Neer CS. Anterior acromioplasty for the chronic impingement syndrome of the shoulder. J Bone Joint Surg Am. 1972; 54: 41-50.

7. Coskun N, Karaali K, Cevikol C, Demirel BM, Sindel M. Anatomical basics and variations of the scapula in Turkish adults. Saudi Med J 2006; Vol 27(9): 1320-5.

8. DePalma AF, Brand RA. Origin and Comparative Anatomy of the Pectoral Limb. Clin Orthop Relat Res 2008; 466(3): 531-42.

9. Wael Amin NE, Mona HMA.A Morphometric Study of the Patterns and Variations of the Acromion and Glenoid Cavity of the Scapulae in Egyptian Population. Journal of Clinical and Diagnostic Research 2015; 9(8): AC08-AC11.

10. Mansur DI, Khanal K, Haque MK, Sharma K. Morphometry of Acromion Process of Human Scapulae and its Clinical Importance amongst Nepalese Population. Kathmandu Univ Med J 2012; 38(2):33-36.

11. Sitha P, Nopparatn S, Aporn CD. The Scapula: Osseous Dimensions and Gender Dimorphism in Thais. Siriraj Hosp Gaz 2004; 56(7): 356-65.

12. Lingamdenne PE, Marapaka P. Measurement and analysis of Anthropometric measurements of the Human Scapula in Telangana Region, India. Int J Anat Res 2016; 4(3): 2677-83.

13. Singh J, Pahuja K, Aggarwal R. Morphometric parameters of the acromion process in adult human scapulae. Indian Journal of Basic Applied Medical Research 2013; 8(2):1165-70. 
Copyright: () the author(s), 2019. It is an open-access article distributed under the terms of the Creative Commons Attribution License (CC BY 4.0), which permits authors to retain ownership of the copyright for their content, and allow anyone to download, reuse, reprint, modify, distribute and/or copy the content as long as the original authors and source are cited.

How to cite this article: Dhindsa GS, Gupta V. Morphometric Study of the Acromion Process and its Clinical Relevance. Asian J. Med. Res. 2019;8(3):AT04-AT08.

DOI: dx.doi.org/10.21276/ajmr.2019.8.3.AT2

Source of Support: Nil, Conflict of Interest: None declared. 